\title{
Les Lumières, le premier partage de la Pologne et le « système politique » de l'Europe
}

The Enligthenment, the first Partition of Poland and the "systeme politique » of Europe

Marc Belissa

\section{(2) OpenEdition}

\section{Journals}

Édition électronique

URL : https://journals.openedition.org/ahrf/10571

DOI : 10.4000/ahrf.10571

ISSN : 1952-403X

Éditeur :

Armand Colin, Société des études robespierristes

Édition imprimée

Date de publication : 1 avril 2009

Pagination : 57-92

ISBN : 978-2-200-92558-1

ISSN : 0003-4436

\section{Référence électronique}

Marc Belissa, « Les Lumières, le premier partage de la Pologne et le "système politique » de l'Europe », Annales historiques de la Révolution française [En ligne], 356 | avril-juin 2009, mis en ligne le 01 juin 2012, consulté le 22 avril 2022. URL : http://journals.openedition.org/ahrf/10571 ; DOI : https:// doi.org/10.4000/ahrf.10571 


\title{
LES LUMIÈRES, LE PREMIER PARTAGE \\ DE LA POLOGNE ET LE «SYSTEME POLITIQUE » DE L'EUROPE
}

Marc BELISSA

\begin{abstract}
En étudiant les textes des "publicistes " des deux dernières décennies de la fin du XVIII siècle sur le " système politique » de l'Europe, on est frappé de constater à quel point le premier partage de la Pologne de 1772 leur apparaît comme le point de départ d'une remise en cause de la politique continentale avant 1789. Pendant la Révolution française, "patriotes » et contre-révolutionnaires ne cessent d'y faire référence pour défendre l'idée qu'une page des relations entre les États a été tournée en 1772. Cette conviction s'est-elle forgée a posteriori ou les contemporains de la première partition l'ont-ils pensée d'emblée comme une rupture fondamentale de l'ordre européen existant ? Le partage de la Pologne apparaît à un courant d'opinion au sein des Lumières, et au-delà pendant la Révolution française, non comme un fait anodin dans une Europe hobbesienne dominée par les intérêts égoïstes des puissances, mais comme un crime contre les droits des nations, ouvrant une nouvelle ère des relations entre les peuples.
\end{abstract}

Mots-clés : Pologne, partition, système politique de l'Europe, droits des peuples.

En étudiant les textes des " publicistes » des deux dernières décennies de la fin du XVIII ${ }^{e}$ siècle sur le "système politique » de l'Europe, on ne peut qu'être frappé de constater à quel point le premier partage de la Pologne de 1772 leur apparaît comme le point de départ d'une remise en cause de la politique continentale avant 1789. Pendant la Révolution française, "patriotes » et contre-révolutionnaires ne cessent d'y faire référence pour défendre l'idée qu'une page des relations entre les États a 
été tournée en 1772. Pour les républicains des années 1795-1799 par exemple, le partage de la Pologne a bouleversé l'équilibre des puissances, la balance européenne a été détruite et les annexions voulues par la République française (Belgique, rive gauche du Rhin) sont justifiées a posteriori par ce crime contre toutes les nations. Certains contre-révolutionnaires eux-mêmes voient dans le premier partage de la Pologne un dangereux précédent qui a ouvert la voie au désordre généralisé provoqué selon eux par l'expansion territoriale de la République française' ${ }^{1}$.

Partant de cette constatation, on peut se demander si cette conviction s'est forgée a posteriori ou si les contemporains de la première partition l'ont pensée d'emblée comme une rupture fondamentale de l'ordre européen existant. Les acteurs politiques, les publicistes des années 1770 ont-ils eu conscience de son importance et de sa portée ?

Si les origines diplomatiques et les conséquences géopolitiques du partage, ainsi que les négociations qui l'entourent, ont été étudiées depuis longtemps par les historiens ${ }^{2}$, le débat politique européen suscité par la partition a été en grande partie ignoré, à l'exception du classique Stanislas Poniatowski et l'Europe des Lumières de Jean Fabre de 1952 et d'un ouvrage paru en 1945 de l'historien anglais David Horn qui s'était intéressé, quant à lui, aux réactions anglaises à cette première partition ${ }^{3}$. Certes, quelques articles et des communications dans des actes de colloques en France et en Pologne ont abordé la réponse de quelques-uns des plus célèbres des philosophes des Lumières, mais ces travaux posent rarement cette question sous l'angle d'un débat politique global au sein des Lumières ${ }^{4}$.

(1) Marc Belissa, Repenser l'ordre européen 1795-1802. De la société des rois aux droits des nations, Paris, Kimé, 2006, p. 53 et suivantes.

(2) Voir notamment Jeremy BLACK, European International Relations 1648-1815, Londres, Houndsmils Palgrave, 2002. Herbert H. Kaplan, The First Partition of Poland, New York, Columbia University Press, 1962. Jerzy T. Lukowski, The Partitions of Poland, 1772, 1793, 1795, London, New York, Longman, 1999. Paul W. Schroeder, The Transformation of European Politics, 1763-1848, Oxford, 1994. Hamish M. Sсотт, The Emergence of the Eastern Powers, 1756-1775, Cambridge, New York, Cambridge University Press, 2001.

(3) Jean FABre, Stanislas-Auguste Poniatowski et l'Europe des Lumières, (1952), rééd. Paris, Ophrys, 1984. David B. Honn, British Public Opinion and the First Partition of Poland, Edinburgh, London, Oliver and Boyd, 1945.

(4) Voir notamment : les actes des colloques Voltaire et Rousseau en France et en Pologne, Éd. de l'Université de Varsovie, 1982, Le siècle de Rousseau et sa postérité, Uniwersytet Warszawski, Instytut Romanistyki, 1998, La France et la Pologne: histoire, mythes, représentations, Françoise Lavocat (dir.), Lyon, PUL, 2000 et Samuel Fiszer, L'image de la Pologne dans l'œuvre de Voltaire, Oxford, Voltaire foundation, 2001. Emanuel Rostworowski, «Voltaire et la Pologne », Studies on Voltaire and the Eighteenth Century, 62, 1968, p. 101-121. 
L'historiographie est, par ailleurs, loin d'être unanime quant à la question des conséquences à court et à long terme du premier partage de la Pologne sur le «système politique de l'Europe». Comme le remarquait Jean Fabre, les historiens allemands ont avancé à la fin du $\mathrm{XIX}^{\mathrm{e}}$ siècle et au début du $\mathrm{XX}^{\mathrm{e}}$ siècle l'idée qu'en raison du " cosmopolitisme » des Lumières, le partage de la Pologne serait passé inaperçu et que les contemporains n'y auraient pas vu un tournant fondamental ${ }^{5}$. $\mathrm{Au}$ début du $\mathrm{XX}^{\mathrm{e}}$ siècle, Sorel voit dans le démembrement le fruit d'un « système de convenance » qui prolonge largement les doctrines et les pratiques de l'Ancien Régime, même s'il remet en cause deux principes du consensus européen : celui de la prescription et celui de la légitimité des acteurs internationaux ${ }^{6}$. Jean Fabre s'oppose à cette interprétation et affirme que le siècle du droit des gens de Vattel et de Rousseau n'accepta pas les faits «avec indifférence, scepticisme ou résignation ». Une conscience européenne - parfois égarée, certes, par la propagande des despotes dits éclairés - existait quant aux affaires polonaises ${ }^{7}$.

Plus récemment, Paul Schroeder dans son classique The Transformation of European Politics, 1763-1848, tend à minorer l'impact du partage en insistant sur l'instabilité des relations internationales à partir de $1763^{8}$. Du point de vue de l'évolution géopolitique, l'affaiblissement de la Porte est, selon Schroeder, un facteur bien plus important que le partage qui lui apparaît, non comme le résultat d'une stratégie des acteurs, mais comme un sous-produit de l'effondrement turc, obligeant les puissances co-partageantes à redistribuer les cartes pour éviter une guerre entre elles. La partition n'est pas un crime sans précédent, comme le disent plusieurs contemporains : la Succession d'Espagne, celle d'Autriche, les plans de partage des possessions européennes de la Porte sont autant de projets, selon Schroeder, qui l'anticipent ${ }^{9}$. De manière paradoxale, le partage est donc selon lui un exemple-type de «coopération internationale » paci-

(5) Jean FABre, Stanislas-Auguste Poniatowski et l'Europe des Lumières, op cit., p. 643.

(6) Albert Sorel, La Révolution française et l'Europe, Paris, 1885-1904, tome 1, p. 40, 89.

(7) Jean FABre, Stanislas-Auguste Poniatowski et l'Europe des Lumières, op. cit., p. 347.

(8) Paul Schroeder, op. cit., chapitre 1, p. 8 et suivantes.

(9) On remarquera pour contredire cette thèse que tous les plans de partages antérieurs prévoyaient non un démembrement d'entités territoriales " historiques », mais une redistribution de la souveraineté sur des entités complètes : personne ne propose de découper la Sicile en trois, ou la Bohême en quatre. Les «états » passent de main en main, mais ne sont pas redécoupés selon la convenance, contrairement à la Pologne. 
fique au XVIII ${ }^{e}$ siècle ${ }^{10}$. Jeremy Black tempère ce propos. Comme Sorel ou Schroeder, il considère que la partition n'est pas fondamentalement nouvelle en soi, mais il admet néanmoins qu'elle a été perçue comme telle par les contemporains, car l'Europe était relativement stable du point de vue territorial depuis 1748. L'alliance des puissances co-partageantes a semblé un danger pour toute l'Europe, car mettant en cause l'équilibre, mais en réalité le démembrement n'a affecté que l'Est du continent ${ }^{11}$.

Ces interprétations correspondent-elles à celles des contemporains de l'événement ? Comment les diplomates, les journalistes et les publicistes ont-ils rendu compte du premier partage de la Pologne en France ? Quelle analyse de ses conséquences à court, moyen et long terme ont-ils développée dans leurs écrits? Ces considérations sont-elles révélatrices d'une conception globale des relations entre les États, et de ce que l'on pourrait appeler des « règles de consensus » fondant l'ordre européen ? Telles sont les questions que cet article entend poser à partir de sources diplomatiques, mais aussi en utilisant les articles et compte rendus des gazettes de langue française, ainsi qu'une partie des brochures, pamphlets, considérations et autres écrits de circonstance provoqués par la situation polonaise et la première partition de 1770 à 1776 environ. En effet, dans cette période, la Pologne est au cœur d'un débat qui met aux prises apologistes et critiques des despotes dits éclairés et qui place au centre de son développement l'avenir des relations entre les peuples en Europe. Des acteurs et des commentateurs aussi différents que Vergennes, le comte de Broglie, Mably, John Lind, l'abbé Baudeau, Carracioli, Voltaire ou Marat utilisent l'expérience polonaise comme un révélateur de l'état de l'Europe des années 1770.

Après avoir rappelé dans un premier temps les grandes lignes du contexte politique, militaire et diplomatique aboutissant au partage, j'aborderai ensuite la manière dont les commentateurs caractérisent la partition : est-elle pensée comme une manifestation spectaculaire - mais finalement peu étonnante - du fonctionnement concret et normal de la société des États européens, fondée sur le droit de la puissance et sur lui seul ? Est-elle au contraire fustigée comme un crime contre l'ordre, le droit positif des traités ou les droits des nations? Enfin, la question des

(10) Idem, p. 18-19 « Poland was sliced up in 1772 not mainly because it was a tempting prize or a danger to European stability [...] but as a device to avoid a wider conflict and help settle more important questions ». " The crime of the first Polish partition rose directly from the rules and needs of standard eighteenth century policy ».

(11) Jeremy BLACK, European International relations, 1648-1815, op. cit., p. 192. 
conséquences à l'échelle polonaise, à celle de l'Europe de l'Est et du continent sera l'objet de la troisième partie, $j$ 'y reviendrai sur la manière dont les contemporains de la Révolution française ont analysé le partage de 1772 comme une brèche dans l'ordre européen d'Ancien Régime.

\section{La marche à la première partition}

À partir du début du XVIII ${ }^{e}$ siècle, la Pologne est confrontée au bouleversement géopolitique de l'Europe de l'Est et du Nord qui voit la Suède déchoir de son rang de grande puissance et la Russie la remplacer comme puissance d'abord régionale, puis européenne. Dès 1717 et la fin de la guerre du Nord, le traité de Varsovie convertit de facto la Pologne en protectorat russe. Sous le règne des rois saxons de la dynastie des Wettin, la Russie et la Prusse consolident leur influence en Pologne en jouant des disputes entre grandes familles de magnats, mais sans jamais réussir à la satelliser complètement.

À la mort d'Auguste III qui survient le 5 octobre 1763, la Russie et la Prusse décident d'encourager l'élection d'un roi piast ${ }^{12}$, car un troisième roi saxon aurait donné un caractère héréditaire à la monarchie polonaise, ce que ne veut à aucun prix la Russie dont la ligne de conduite est de conserver des institutions que les Tsars considèrent comme « anarchiques » et donc comme susceptibles d'affaiblir leur voisin. La Prusse, alliée de la Russie, défend la même politique et signe le 11 avril 1764 un traité avec la Russie qui stipule la garantie conjointe des constitutions suédoise et polonaise.

L'ancien amant de Catherine II et écuyer de Lithuanie, StanislasAuguste Poniatowski, est élu le 7 septembre 1764. La France - qui était favorable à l'élection d'un roi saxon puis qui avait soutenu un concurrent polonais - est battue et son ascendant ne cesse de décliner malgré l'engagement du Secret du roi. Stanislas-Auguste se présente comme un monarque éclairé qui entend renforcer le pouvoir royal, s'inspirer de l'Angleterre et abolir le liberum veto pour faire de la diète un parlement, mais ses réformes se heurtent aux résistances des grandes familles et des puissances voisines.

Un plan de restriction du liberum veto est proposé à la diète de 1766 . La réaction des puissances et des magnats est immédiate. Des confédérations nobiliaires dissidentes, appuyées par les soldats russes, sont mises

(12) Les piasts étaient une dynastie de rois et de ducs ayant gouverné la Pologne au MoyenÂge. Par extension, les piasts étaient censés être au XVIII siècle les descendants de cette dynastie. 
en place à Thorn et à Sluck en mars 1767 (aucune des deux ne recueille plus de quelques centaines de signatures). Elles exigent l'égalité politique pour les dissidents orthodoxes et protestants, et sont soutenues par la Russie, mais aussi par la Prusse, l'Angleterre, la Suède et le Danemark. En juin, ces deux confédérations se réunissent avec les républicains « sarmates », pour créer la confédération générale de Radom le 23 juin 1767 qui demande la restauration de l'ancien gouvernement (elle recueille plus de 70000 signatures). Le $1^{\text {er }}$ décembre, une loi sur les dissidents est signée qui leur concède l'égalité des droits politiques avec les catholiques. L'ambassadeur russe Repnin contraint la diète à admettre Catherine II comme protectrice de la constitution polonaise dans le traité perpétuel de Varsovie du 24 février 1768. La Pologne est désormais entièrement vassalisée.

En réaction à cette mise sous tutelle, une confédération opposée à l'occupation russe et au roi, considéré comme leur acolyte, s'organise dans la ville de Bar en Podolie le 29 février 1768. Son programme est la défense de la foi, menacée par les privilèges accordés aux dissidents, et des « libertés » polonaises. La France soutient l'initiative et pousse l'Empire ottoman à déclarer la guerre le 6 octobre 1768 à la Russie pour faire diversion. Elle envoie des conseillers et des officiers comme Dumouriez pour encadrer les troupes confédérées. L'Autriche reste dans une neutralité bienveillante puisqu'elle leur permet de rester sur son territoire et de s'y ravitailler. En 1769, sur les conseils de la France, une confédération générale installée à Biala sur la frontière de la Silésie autrichienne prend la suite de celle de Bar et la guérilla se poursuit, déchirant le pays. Le 3 novembre 1771, une tentative d'enlèvement du roi pour l'obliger à abdiquer échoue. Les partisans de Stanislas-Auguste et des Russes présentent cette action comme une tentative de meurtre commandité par le fanatisme tyrannicide des catholiques. Même si les Russes n'arrivent pas à battre la confédération, les troupes de cette dernière se rendent progressivement, d'autant que la Turquie essuie défaite sur défaite.

Pendant ce temps, l'idée d'un partage de la Pologne a fait son chemin. Les négociations préparatoires au partage sont complexes ${ }^{13}$. Il est incontestable que la Prusse a pris l'initiative de ce partage, alarmée qu'elle était par la montée de la Russie et craignant plus que tout une alliance austro-russe. En février 1769, un premier plan est proposé par l'envoyé prussien à Saint-Pétersbourg. La Russie ne donne pas suite. La Prusse tente un rapprochement avec l'Autriche lors des entrevues entre Frédéric 
II et Joseph II en août 1769 et en septembre 1770. Du 12 octobre 1770 au 31 janvier 1771, le prince Henri de Prusse (le frère de Frédéric II), en visite à Saint-Pétersbourg, tente de faire admettre le principe du partage à la Russie, ce sera chose faite à l'automne, puis tout au long de 1771, la Prusse tente de faire de même avec l'Autriche. À la fin du mois d'août, les choses avancent, un accord russo-prussien est signé en février 1772, puis, malgré ses réticences, l'Autriche se joint à la curée en août. Le traité de partage - en fait trois conventions bilatérales - est signé en septembre. L'armée polonaise ne peut rien contre les troupes des puissances co-partageantes. Quelques contingents de confédérés mènent des actions à l'automne 1772, mais la plupart abandonnent le combat. Le soutien réclamé par Stanislas-Auguste ne vient pas et les puissances ne bronchent pas. Bientôt d'ailleurs, d'autres événements en Europe contribuent à faire passer la Pologne au second plan. Le coup d'État réalisé le 18 août 1772 par Gustave III de Suède met fin à « l'ère de la liberté » et occupe rapidement la première place dans les gazettes. Le partage est finalement voté par une diète aux ordres le 30 septembre 1773. La Pologne perd quatre millions d'habitants (un tiers de sa population) et un quart de son territoire. Le démembrement de la Pologne révèle l'impuissance de la France et l'indifférence de l'Angleterre; la Porte est écrasée et doit signer un traité très défavorable à Kütchük-Kaynardji le 21 juillet 1774 .

Il restait à réorganiser ce qui subsistait de la république de Pologne. La réalité du pouvoir revenait à l'ambassadeur russe, le comte Otto Magnus de Stackelberg, qui dirigeait les troupes stationnées en Pologne. L'acte final de la réorganisation de la république se joua dans la diète de 1776. En octobre, celle-ci adopta tout ce que les Russes et le roi lui demandaient, et notamment l'extension des pouvoirs du conseil permanent et le droit de nomination des officiers au roi. Ce système devait rester en place jusqu'à la diète de 1788 qui ouvrit un nouveau chapitre de l'histoire de la république polonaise.

\section{Un crime contre le droit des nations?}

Contrairement à ce qui a été affirmé parfois par l'historiographie ${ }^{14}$, le premier partage de la Pologne n'a pas été seulement reçu dans le silence, gêné ou complice, mais aussi par un débat sur sa nature et ses conséquences. Si Jean Fabre a pu écrire qu'en présence du crime, la philosophie

(14) Voir Jean FABre, Stanislas-Auguste Poniatowski et l'Europe des Lumières, op. cit., p. 643 . 
se lavait les mains ${ }^{15}$, c'est parce qu'il s'était penché surtout sur les écrits des voltairiens et des encyclopédistes, qui, effectivement, en tant que défenseurs plus ou moins affirmés de l'action des despotes dits éclairés, étaient objectivement dans le camp des partisans des puissances co-partageantes, mais une production importante d'écrits de circonstance s'affirme au contraire dans le camp de ceux qui sont scandalisés par la partition et qui le font savoir. Alors que les puissances co-partageantes tentent assez faiblement de se justifier en s'appuyant sur d'anciennes "prétentions » ou sur la nécessité d'agir face à "l'anarchie polonaise », plusieurs brochures, parfois reprises dans la presse francophone, s'emploient à démolir ces justifications et polémiquent avec les défenseurs du despotisme dit éclairé. Stanislas-Auguste Poniatowski lui-même tente d'utiliser la presse pour protester contre la partition, rassembler les puissances neutres autour de la cause polonaise et pour se présenter comme le seul recours dans la situation de crise politique de la Pologne amputée d'une partie de sa population et de son territoire.

Quelques semaines après l'entrée effective des troupes autrichiennes dans l'enclave de Zips et dans les quatre starosties revendiquées par les Habsbourg qui donne le signal du partage effectif, les trois puissances co-partageantes font connaitre les textes des traités bilatéraux qui les unissent dans le partage de la Pologne. Le texte du manifeste des trois cours est reproduit et commenté dans toutes les gazettes et journaux ${ }^{16}$. L'occupation de la Pologne y est justifiée par «l'esprit de faction, les troubles et la guerre intestine dont est agité depuis tant d'années le royaume de Pologne, et l'anarchie qui chaque jour y acquiert de nouvelles forces, au point d'y anéantir toute autorité d'un gouvernement régulier, donnant de justes appréhensions de voir arriver la décomposition totale de l'État, troubler le rapport des intérêts de tous les voisins, altérer la bonne harmonie qui subsiste entre eux, et allumer la guerre générale ». Devant cette situation, les puissances co-partageantes ont entamé des négociations pour aboutir au « rétablissement de la tranquillité de la Pologne ». Mais, dans le même temps, les puissances « ayant à sa charge des prétentions et des droits aussi anciens que légitimes dont elles n'ont

(15) Idem, p. 255.

(16) Tous les textes des manifestes et déclarations des puissances co-partageantes sont reproduits dans Georg Friedrich de MARTENS, Recueil des principaux traités d'alliance, de paix, de trêve, de neutralité... conclus par les puissances de l'Europe depuis 1761, Göttingen 1801 (1 ${ }^{\mathrm{re}}$ éd. 1791), Actes relatifs au premier partage de la Pologne (1772-1776), tome II, p. 89-103. On les trouve également dans la Gazette de La Haye, la Gazette de Cologne, la Gazette de Leyde et la Gazette d'Utrecht. 
jamais pu avoir raison, et qu'elles risquent de perdre sans retour, si elles ne prennent pas des moyens de les mettre à couvert et de les faire valoir elles-mêmes » décident de prendre ce qui leur est dû tout en restaurant « la tranquillité et le bon ordre dans l'intérieur de cette république ». La déclaration additionnelle des trois cours de septembre 1772 précise qu'elles ont convenu «de faire valoir, chacun en particulier, les droits anciens » qu'elles ont sur certaines parties de la Pologne et de les réunir à leurs couronnes. Les puissances déclarent également «que chacune d'entre elles sera prête à justifier en temps et en lieu » ces prétentions et droits «par des documents et des déductions solides, et sur lesquelles l'état de la République ne leur permet pas de pouvoir jamais espérer justice par les voies ordinaires ».

Malgré cette promesse, seul le roi de Prusse dans des Lettres patentes du 13 septembre 1772 prendra la peine d'expliquer en quoi consistent les droits et prétentions sur lesquels il s'appuie ${ }^{17}$. La Russie se contente du fait, et de la réponse du baron de Stackelberg au roi de Pologne le 18 septembre, tandis que Marie-Thérèse - qui aurait déclaré avoir une « très mince opinion » de ses titres ${ }^{18}-$, ne daignera produire aucune justification si ce n'est une déclaration le 11 septembre prononçant l'annexion au nom de la convenance ${ }^{19}$. Les Lettres patentes du roi de Prusse... recourent abondamment à l'histoire pour faire valoir son bon droit: "La Couronne [de Pologne] a depuis plusieurs siècles injustement possédé et retenu aux ducs de Poméranie, et après eux, à la maison électorale de Brandebourg, la partie de la Poméranie, située entre les frontières présentes de ce duché et les rivières de la Vistule et de la Netze ». Les droits historiques de la Prusse sont censés remonter à 1295 et l'occupation de la part prussienne de la Pologne est présentée comme un dédommagement dû pour cette usurpation multiséculaire ${ }^{20}$. La déclaration russe de Stackelberg du 18 septembre se contente de justifier le partage par la nécessité et la convenance : «Les puissances voisines de la Pologne, ont été souvent entraînées dans les troubles que les interrègnes ont excités dans le Royaume ». La Russie a cherché à travailler à la concorde dans la nomination du roi de Pologne pour éviter les troubles et « à faire rectifier plusieurs abus dans la constitution de l'État ». Grâce à la Russie et à ses alliées, l'élection de Stanislas-

(17) La Gazette (de France), n ${ }^{\circ} 81$ du 9 octobre 1772, p. 738, 740.

(18) Albert Sorel, La Révolution française et l'Europe, op. cit., tome 1, p. 40.

(19) B. Cuttoli, La Pologne au XVIII siècle et le droit international. Thèse pour le doctorat ès sciences politiques et économiques, Paris, E. Basset, 1912, p. 131.

(20) Georg Friedrich de Martens, Recueil des principaux traités, op. cit., p. 100. 
Auguste présageait d'une ère de tranquillité, mais «l'esprit de discorde » s'est emparé de la nation: "Les citoyens s'armèrent les uns contre les autres, des factions usurpèrent l'autorité légitime, ils en abusèrent au mépris des lois, du bon ordre et de la sûreté publique. [...] Les liaisons naturelles entre les nations limitrophes font déjà éprouver aux puissances voisines de la Pologne, les plus fâcheux effets de ces désordres. Ils les obligent depuis longtemps à des mesures de précaution les plus coûteuses, pour assurer la tranquillité de leurs propres frontières, et ils les exposent, par l'incertitude des suites de la destruction de ce royaume, au danger de voir peut-être altérer l'amitié et la bonne harmonie qui subsistent entre elles ». Ces troubles « entraîneraient vraisemblablement des changements dans le système politique de cette partie de l'Europe $»^{21}$.

À l'annonce de la partition, même les partisans les plus décidés de Frédéric II et de Catherine II parmi les philosophes et les publicistes sont surpris, car les négociations en vue du partage ont été menées dans le secret et avec rapidité. Ainsi, Voltaire est d'abord incrédule, mais applaudit quand même, tout en pestant en privé contre le cynisme des prétentions des puissances co-partageantes, puis il se rétracte, mais très discrètement pour ne pas trop être entendu à Berlin et Saint-Pétersbourg. Catherine II se justifie sur un mode ironique tout voltairien en écrivant au philosophe : « Ne trouvez-vous pas raisonnable que ceux qui ferment les oreilles à la Raison payent les violons? $\gg{ }^{22}$ Penaud, Voltaire fait son courtisan dans une lettre à Frédéric II du 16 octobre 1772, il le félicite pour la médaille qui vient d'être frappée représentant le territoire prussien avec la partie annexée de la Pologne et lui envoie les vers suivants : "La paix a bien raison de dire aux palatins/Ouvrez les yeux, le diable vous attrape,/ Car vous avez à vos puissants voisins/Sans y penser longtemps servi la nappe./ Vous voudrez bien trouver bel et beau/ Que ces voisins partagent le gâteau $^{23}$. » Dans une autre lettre à Frédéric, il ironise sur Stanislas-Auguste : «Le roi de Pologne [...] a bien justifié l'ancien proverbe des Grecs, la moitié vaut mieux que le tout $»^{24}$. Pourtant, on sent poindre dans une lettre ultérieure une certaine rancœur contre Catherine II qui l'a utilisé pour ses propres intérêts : « Je fus attrapé comme un sot, quand je crus bonnement,

(21) Idem, p. 103.

(22) Cité par Jean Fabre, Stanislas-Auguste Poniatowski et l'Europe des Lumières, op. cit., p. 326 .

(23) François Marie Voltaire, Correspondence of Voltaire, Theodore Besterman (ed), Genève, 1963, lettre à Frédéric II, n 16904. Cité par Jean FABRE, op. cit., p. 327.

(24) Idem, lettre $n^{\circ} 18538$. 
avant la guerre des Turcs, que l'impératrice de Russie s'entendait avec le roi de Pologne pour faire rendre justice aux dissidents et pour établir seulement la liberté de conscience. Vous autres rois, vous nous en donnez bien à garder : vous êtes comme ces dieux d'Homère, qui font servir les hommes à leurs desseins, sans que ces pauvres gens s'en doutent $»^{25}$. Malgré sa grande méfiance à l'égard de Frédéric II, Diderot se tait et fait savoir à Catherine II que le gouvernement français a pris acte de la partition sans intention de réagir ${ }^{26}$. Grimm se moque du projet de Rousseau et du sort de «l'anarchie » polonaise ${ }^{27}$.

Le roi de Pologne réagit immédiatement au manifeste des trois puissances en rendant publique une déclaration reproduite elle aussi dans toutes les gazettes. Il y « déclare de la manière la plus solennelle, qu'il regarde l'occupation actuelle des provinces de la Pologne par les cours de Vienne, de Pétersbourg et de Berlin, comme injuste, violente, et contraire à ses légitimes droits. Il en appelle aux traités garants des appartenances de son royaume $\gg{ }^{28}$. Stanislas-Auguste essaie de s'appuyer sur la France et sur l'Angleterre pour contrebalancer l'influence des puissances co-partageantes et tente de mobiliser à son profit l'opinion éclairée en utilisant le réseau de ses pensionnés dans les gazettes européennes. Ainsi, le rédacteur du Courrier du Bas-Rhin, pensionné par le roi de Pologne et... le roi de Prusse, ceux de la Gazette de Leyde et ceux de la Gazette de France, cette dernière subventionnée par le ministère français des Affaires étrangères, sont sollicités par Poniatowski pour insérer des articles mettant en scène le roi face aux puissances co-partageantes, mais aussi face à 《l'anarchie » des diètes et de la noblesse « conservatrice $»^{29}$. Stanislas envoie lui-même des articles « anonymes », comme par exemple celui du 6 août 1772 au Courrier du Bas-Rhin dans lequel il se présente comme le seul recours contre la partition qui s'annonce. Il accuse le gouvernement polonais d'être la cause principale des malheurs de la Pologne et plaide pour un renforcement du pouvoir royal ${ }^{30}$.

(25) Ibid., lettre ${ }^{\circ} 18227$.

(26) Denis Diderot, Euvres politiques, Robert Laffont, Paris, 1995, p. 229.

(27) Correspondance Littéraire, Paris, Garnier, 1879, Kraus reprint, 1968, tome 10 ; février 1773, p. 180.

(28) Gazette de Leyde, n ${ }^{\circ}$ du 10 novembre 1772.

(29) Annie Rivara « Images de Stanislas Poniatowski dans quelques gazettes dans les années 1773-1775 », dans La France et la Pologne : histoire, mythes, représentations, op. cit., p. 280

(30) Cité par Roland Butterwick, Poland's last King and English Culture : Stanislaw August Poniatowski, 1732-1798, Clarendon Press, 1998, p. 247. 
Dès la publication des manifestes justificatifs des puissances, la presse et les publicistes s'en emparent, soit pour en prendre acte, soit pour les critiquer, soit pour les défendre contre les attaques. D'une manière générale, les gazettes et les journaux se contentent de reproduire les textes officiels en y ajoutant parfois quelques commentaires, mais leur tonalité générale se veut plutôt neutre. Quelques journaux sont plus critiques et laissent entendre que les «droits et prétentions» des puissances, et notamment de la Prusse qui a pris la peine de les détailler, sont plus que douteux et ne sont que de pâles justifications sur le terrain du droit public. Ainsi le Journal politique de Bruxelles adopte le ton de l'ironie vis-à-vis des prétentions territoriales des puissances pendant les négociations de frontières qui suivent la partition en $1774^{31}$. L'année suivante, il publie en intégralité la préface de l'ouvrage pro-polonais de Carracioli, La Pologne, telle qu'elle a été, telle qu'elle est, telle qu'elle sera et d'une manière générale, le journal manifeste sa sympathie et sa solidarité envers la malheureuse Pologne démembrée. Le Journal historique et politique de Genève publie le 10 juillet 1773 un long article sur les fondements historiques des prétentions prussiennes sur la Pologne : l'article conclut que les preuves sont au moins très discutables, et que, de toute manière, elles sont détruites par les traités ultérieurs (et notamment par celui de 1764) par lesquels le roi de Prusse promet de respecter l'intégrité du territoire de la République ${ }^{32}$.

Un Anglais joue un rôle particulier dans la défense de la Pologne et dans la contre-propagande dirigée contre les puissances co-partageantes, il s'agit de John Lind ou Lindsey. John Lind est issu d'une famille d'Édimbourg. D'abord chapelain de l'ambassade anglaise à Constantinople, il séjourne en Pologne, devient conseiller et précepteur du neveu de Stanislas-Auguste puis dirige l'école des cadets de Varsovie. Selon David Horn, Lind joue en quelque sorte un rôle de coordinateur des publications, des pamphlets et des articles en défense de la Pologne publiés en Angleterre, et même dans la presse francophone, en passant par le relais du ministère des Affaires étrangères de Louis XV. Ainsi, le premier commis Gérard de Rayneval traduit plusieurs de ses textes en français et leur donne une large diffusion.

L'ouvrage principal de Lind est les Letters concerning the present state of Poland, de 1773, dont de larges extraits sont traduits et repris dans

(31) Journal politique de Bruxelles, tome 1, octobre-décembre 1774.

(32) Journal historique et politique, $\mathrm{n}^{\circ}$ 19, 10 juillet 1773, p. 135 
les brochures publiées en France ${ }^{33}$. Il s'agit d'une condamnation globale et sans réserve de la partition qui est fustigée comme un crime contre le droit des nations et le droit des gens ${ }^{34}$. Aucune des arguties des puissances co-partageantes n'a la moindre valeur : «Les ministres de Pétersbourg sont habitués à apparaître sans rougir devant le tribunal de l'opinion pour défendre n'importe quelle cause. Les nouveaux alliés de la Russie, avec toute leur religion et leur philosophie ne sont pas plus scrupuleux ou pudiques $»^{35}$. Le manifeste des puissances n'est qu'un mélange adroit de mensonge et de demi-vérités. Il est de toute façon facile pour les despotes de trouver des plumes mercenaires pour prouver n'importe quoi, mais cela ne change rien au crime contre le droit ${ }^{36}$. Lind s'en prend ironiquement aux journaux subventionnés par la Prusse - et notamment au Courrier du Bas-Rhin - qui, selon lui, n'ont pas osé publier l'intégralité de leur défense des prétentions prussiennes, tellement les «droits» prussiens sont évidemment légitimes aux yeux de toute l'Europe ! La cause principale de la partition est - sans surprise - «l'anarchie » polonaise et surtout l'ambition destructrice des puissances co-partageantes que la France et l'Angleterre doivent contenir par leur union ${ }^{37}$.

Lind est aussi sans doute l'auteur du Partage de la Pologne en 7 dialogues en forme de drame publié début 1774 sous le nom de « Gotlieb Pansmouser» ou de «Theophilus Lindsey ». Le texte a été traduit par Rayneval ${ }^{38}$. Il s'agit d'une pochade mettant en scène Frédéric II, Catherine II et Marie-Thérèse, discutant de la justification de leur forfait. Tout le texte est une longue diatribe contre l'amoralisme des puissances co-partageantes et leur mépris à l'égard des droits des nations, des princes et de l'humanité. Ainsi, le roi de Prusse demande à ses complices un manifeste " pour colorer d'une apparence d'équité aux yeux du public, une conduite qui n'a guère respecté ce que les hommes appellent justice $»^{39}$. Il fait l'apologie de la «philosophie moderne » qui ne respecte plus les droits des peuples : «Je ne pense pas que le monde (quelque avancé qu'il soit dans l'âge d'or de la philosophie et de la liberté) soit encore assez parfait

(33) John Lind, Letters concerning the Present State of Poland, the $2^{\mathrm{d}}$ edition, London, printed for Tom Payne, 1773.

(34) Idem, p. 4.

(35) Ibid., notre traduction.

(36) Ibid., p. 150.

(37) Ibid., 298.

(38) Théophilus Lindsey, Le Partage de la Pologne..., Londres, 1776, Le Partage de la Pologne, en 7 dialogues en forme de drame..., Londres, (S. d.).

(39) Idem, p. 5. 
pour entendre avec quelque patience l'exposé sincère et complet des principes qui nous dirigent, et des vues que nous proposons. Il est vrai que la vertu n'est pour les Rois qu'un vieux fantôme qui bientôt même disparaîtra totalement, mais le peuple tient encore à un reste de préjugé et l'on n'a pas encore réussi à abolir entièrement l'usage de rendre quelques faibles hommages à cette antique déesse qui depuis longtemps a perdu sa balance et ses poids $»^{40}$. Dans la coulisse, le roi de Pologne commente cette profession de foi en qualifiant ses collègues de " troupe de voleurs »! L'impératrice de Russie n'est pas inquiète, elle est sûre que les philosophes stipendiés feront leur travail : « Nous ne manquons pas de prétexte pour colorer nos prétentions, Berlin n'est-il pas le centre de la nouvelle philosophie ? Votre Académie ne renferme-t-elle pas des Sophistes habiles qui à force d'écrits puissent entraîner les hommes dans leurs principes? » Elle suggère même l'utilisation de Voltaire, mais Frédéric II s'y oppose sous le prétexte qu'on ne peut pas compter sur lui, car sa manie des fausses citations est trop visible ${ }^{41}$ ! Le roi de Prusse ne cache pas que la partition de la Pologne est un événement fondateur, car il impose l'idée que ce qui lui convient est toujours légitime, car la morale est identique à l'intérêt. Il avoue tout de même « que si on consulte les vieilles notions, notre projet est injuste, violent, barbare, abominable, j'avoue aussi que ces notions ne sont pas faciles à effacer », mais heureusement Hume, Helvétius et Diderot l'aident à faire « cesser le spasme » de sa conscience ${ }^{42}$. La partition « fronde ouvertement tous les préjugés de l'éducation, les droits prétendus de l'humanité, et le sens commun; il insulte à la patience des hommes ». Rien, à première vue, de plus choquant que de « priver un souverain d'une partie de ses États, sans autre prétexte que quelques expressions douteuses renfermées dans de vieux parchemins, et des prétentions auxquelles on a renoncé par les traités les plus solennels, les plus précis et les plus récents $\rangle^{43}$. Les deux impératrices ne se privent évidemment pas d'acquiescer à ce propos de celui qui apparaît comme un athée machiavéliste dirigeant toute l'opération à son profit.

Les Droits des trois puissances alliées sur plusieurs provinces de la république de Pologne est peut être également l'ouvrage de Lind, il a aussi été traduit par Rayneval. Ce pamphlet plus austère que le texte précédent est publié en 1774 avec un autre ouvrage intitulé Réflexions d'un

(40) Ibid, p. 6.

(41) Ibid., p. 10.

(42) Ibid., p. 12.

(43) Ibid., p. 13. 
gentilhomme Polonais sur les lettres-patentes \& prétentions de ces trois puissances sans doute écrit par Felix Lojko, le publiciste du roi de Pologne ${ }^{44}$. Ces deux volumes sont accompagnés de nombreuses pièces justificatives. Il s'agit d'une réponse, très longue et très argumentée, aux prétentions et droits des puissances co-partageantes. Frédéric II y est présenté comme un nouveau candidat à la monarchie universelle, cherchant à forger des fers pour toute l'Europe ${ }^{45}$. Le but avoué de l'ouvrage est de permettre à tous de participer au grand procès des prétentions et d'exposer la nullité et l'insuffisance de ces droits, car la cause des Polonais est celle de toutes les nations. La préface se clôt d'ailleurs par cet appel : «Monarques de la terre, respectez les droits, la liberté des peuples! Nations, sacrifiez tout au maintien de vos droits, de votre liberté ! $»^{46}$

D'autres textes anonymes paraissent en France comme par exemple l'Examen du système des cours de Vienne, de Pétersbourg et de Berlin concernant le démembrement de la Pologne de $1773^{47}$. Le texte pose deux questions : le partage est-il juste ? Est-il utile pour l'Europe ? Pour y répondre, il faut se tourner vers les principes de la morale, du droit des gens et de la politique : « Si les titres des prétentions des trois cours sont bons et ceux de la Pologne ne le sont pas : le système est juste. S'il est conforme à l'intérêt général des nations de l'Europe, et aux intérêts particuliers de chacune des trois puissances alliées : le système est utile $»^{48}$. La première question est vite décidée d'après «les maximes du droit des gens et les traités solennels », la cause des Polonais est bonne, les prétentions des puissances sont insoutenables. L'auteur revient sur les principes du consensus qui fondent selon lui le système politique de l'Europe : il existe «certaines maximes et lois de convention, fondées sur le droit naturel et l'utilité générale, que, depuis deux cents ans, on trouve religieusement observées par les puissances de l'Europe dans leur conduite réciproque », elles « ont donné lieu de regarder cette partie du monde comme une espèce de république, dont les nations, qui la composent, sont les membres ». Première de ces maximes : ne pas laisser opprimer les faibles

(44) Theophilus Lindsey, Les Droits des trois puissances alliées sur plusieurs provinces de la république de Pologne suivi de Réflexions d'un gentilhomme polonais sur les lettres-patentes \& prétentions de ces trois puissances; avec une préface de l'éditeur pour servir d'introduction, Londres, 1774.

(45) Idem, XXII.

(46) Ibid., p. XXXV.

(47) Examen du système des cours de Vienne, de Pétersbourg et de Berlin concernant le démembrement de la Pologne, Londres, 1773.

(48) Ibid., p. 3-4. 
par les grandes puissances, deuxième maxime : la prescription. Les lois de convention sont les traités qui engagent non seulement les parties contractantes, mais aussi les puissances garantes et leurs alliées, c'est-àdire une grande partie des puissances de l'Europe au bout du compte. Les puissances co-partageantes foulent aux pieds les lois les plus respectables et ruinent donc le système général de l'Europe. L'insuffisance des prétentions de Sa Majesté Prussienne sur la Grande-Pologne démontrée, paraît en $1773^{49}$. D'emblée l'auteur se place sur le terrain de l'intérêt de l'Europe entière : les puissances ne sont pas comptables de leurs actions seulement à leurs consciences ou à Dieu, mais aussi à leurs peuples, à tous les princes et à la postérité ${ }^{0}$.

Les Observations sur les déclarations des cours de Vienne, de Pétersbourg et de Berlin au sujet du démembrement de la Pologne paru en 1773 suscite un débat puisque les propagandistes de Frédéric II daignent débattre avec son auteur ${ }^{51}$. Le ton est en effet assez violent à l'égard des prétentions des puissances co-partageantes qui « ne peuvent servir qu'à démontrer l'injustice que ces Cours commettent contre cette république et les dangers dont elles menacent le reste de l'Europe $»^{52}$. L'absence de manifeste de la part de la Russie et de l'Autriche est une preuve supplémentaire de la faiblesse juridique de leurs prétentions. Le texte revient sur la question des responsabilités respectives : "Toute l'Europe sait que l'Impératrice de Russie [...] s'est rendue la maîtresse absolue en Pologne, qu'elle y a fait le roi, qu'elle y a dicté, à main armée, les lois qu'elle a voulues, qu'elle en a changé le gouvernement intérieur. Toute l'Europe éclairée sait également qu'une pareille entreprise viole le droit de la nature et des gens, renverse l'indépendance des états, et sape le fondement des corps politiques $»^{53}$, car le premier principe de la société des États est leur indépendance réciproque. Les Observations reconnaissent sans mal que certains confédérés ont commis des crimes, mais cela ne saurait justifier l'intervention des puissances : «S'emparer des plus belles provinces d'un royaume, sous le prétexte de lui rendre la tranquillité et de lui marquer des limites naturelles, c'est déclarer à la face de l'univers, que l'équité, la vérité et la bonne foi, ne sont que des noms dont on se joue au gré de ses

(49) L'insuffisance des prétentions de Sa Majesté Prussienne sur la Grande-Pologne démontrée, Londres, 1773.

(50) Ibid., p. V.

(51) Observations sur les déclarations des cours de Vienne, de Pétersbourg et de Berlin au sujet du démembrement de la Pologne, Londres, s. n., 1773.

(52) Ibid., p. 5.

(53) Ibid., p. 10. 
intérêts $»^{54}$. Contre l'argument avancé par les trois cours que l'anarchie polonaise leur faisait du tort, l'auteur ironise : «La Pologne, dépourvue d'armes, et de troupes, réduite à une espèce de nullité qui, dans le système politique, l'approche du néant, faisait peur aux Cours de Vienne, de Pétersbourg et de Berlin. Quelle dérision! $\gg{ }^{55}$ Le fait que les trois puissances soient d'accord pour commettre le partage ne lui donne aucune légitimité. La morale ne cesse pas d'unir les nations, l'ignorer revient à se conduire comme les sauvages que les Européens se flattent de ne pas être :

«Les rois, quelques puissants qu'ils soient, ne cessent pas d'être des hommes, et à cet égard, les mêmes devoirs de justice et d'équité les obligent les uns envers les autres, de la même manière que les derniers de leurs sujets. Cette jurisprudence nouvelle, si elle était introduite, serait digne du Code des Sauvages d'Amérique. Deux ou trois hordes de ces barbares se communiqueront réciproquement leur dessein de s'emparer des possessions chétives d'une horde voisine et elles s'en empareront. Nous crierions en Europe contre un pareil brigandage, nous détesterions les mœurs de ces peuples féroces, et c'est en Europe, c'est du Cabinet de trois cours policées, que nous voyons émaner des motifs d'usurpation qui feraient honte aux barbares mêmes. [...] Le Droit des gens est dans la bouche des souverains quand ils se croient lésés ; mais ils perdent ordinairement les principes de vue, lorsque le droit de convenance offre à leur ambition les moyens faciles de s'agrandir... $\gg^{56}$

L'étalage des prétentions historiques des puissances fait l'impasse sur le principe fondamental qui fonde le droit public de l'Europe, c'est-àdire celui de la prescription. Remonter au XIII ${ }^{\mathrm{e}}$ siècle pour argumenter sur les droits des ducs de Poméranie est une plaisanterie puisque les traités de Wehlau et d'Oliva par lesquels la Prusse reconnaît et garantit formellement les frontières et les possessions de la République de Pologne sont bien postérieurs. La possession des domaines que les puissances ont enlevés à la Pologne est donc illégale, et si la raison d'État leur permet « la jouissance des provinces envahies contre la foi des serments et des traités, les lois de la conscience et de la saine raison la leur interdisent ; et malgré leur possession actuelle, les Polonais, ou plutôt le roi et la république de Pologne ont en leur faveur et la justice et l'équité $»^{57}$. Aussi n'y a-t-il personne qui ne soit persuadé que le partage «n'est fondé que sur des motifs frivoles et

(54) Ibid., p. 15.

(55) Ibid., p. 18.

(56) Ibid., p. 23.

(57) Ibid., p. 30. 
des principes insoutenables », qu'il est l'ouvrage de la force et de la violence, « une usurpation manifeste, une injustice criante », et qu'il présente au reste de l'Europe les conséquences les plus alarmantes ${ }^{58}$.

La violence du ton et la mise en cause des princes suscitent une contre-propagande et notamment deux brochures, intitulées simplement Analyse d'une brochure, qui porte le titre d'Observations sur les déclarations des cours de Vienne, de Pétersbourg et de Berlin... (attribuée à Feliks Lojko) et Lettre historique et politique d'un gentilhomme polonais adressée à son ami à l'occasion des Observations... qui entendent, non défendre l'honneur des monarques qui ne peut être égratigné par des folliculaires, mais qui veulent faire connaître la vérité à un public censé être peu au fait des affaires de Pologne ${ }^{59}$. Les deux auteurs se présentent comme des Polonais partisans d'une vigoureuse réforme des institutions de la République, d'une disparition du " joug d'une aristocratie oppressive », et qui espèrent que le soutien des puissances la permettra.

Les deux contre-pamphlets insistent d'abord sur l'inconvenance du style et de la mise en cause des manifestes des puissances. La hardiesse, les insultes à l'autorité, la censure de la conduite des monarques, les « interprétations insultantes des actions et des démarches des souverains les plus respectables de l'Univers » sont un scandale qui ne devrait pas rester impuni ${ }^{60}$. La défense de la partition passe par une condamnation vigoureuse de « l'anarchie polonaise », du fanatisme supposé des confédérés et par l'idée que les Polonais étaient dans l'incapacité de se réformer, la République ayant cessé d'être un interlocuteur légitime dans la sphère des relations entre les États. Les deux auteurs reprennent les lieux communs du discours sur le « retard » polonais ${ }^{61}$, sur l'avidité de la noblesse et sur l'esclavage supposé de sa population : «Qu'on se représente un pays d'une assez grande étendue, fertile et favorisé de tous les dons de la nature, habité par plusieurs millions d'individus malheureux, qui gémis-

(58) Ibid., p. 36.

(59) Analyse d'une brochure, qui porte le titre d'Observations sur les déclarations des cours de Vienne, de Pétersbourg et de Berlin au sujet du démembrement de la Pologne, s1, 1773. Lettre historique et politique d'un gentilhomme polonais adressée à son ami à l'occasion des observations qui ont paru au mois de janvier sur les déclarations des cours de Vienne, Pétersbourg et Berlin au sujet du démembrement de la Pologne, sl., 1773.

(60) Lettre historique..., op. cit., p. 6.

(61) Sur l'image de la Pologne à l'époque des Lumières, voir Alain GuÉRY, « La Pologne vue de France au XVIII ${ }^{\mathrm{e}}$ siècle ", Cahiers $d u$ CRH, avril 1991, n ${ }^{\circ}$, p. 35 à 53., Larry WoLfF, Inventing Eastern Europe. The Map of Civilization in the Mind of the Enlightenment, Stanford, Stanford University Press, 1994. Michel MARTY, Voyageurs français en Pologne durant la seconde moitié du XVIII siècle, Paris, Honoré Champion, 2004. 
sent sous l'esclavage le plus rude, au point que, confondus avec leurs bestiaux, ils n'ont pas même la propriété du pain qui les nourrit. Ces esclaves dont la condition est pire que celle des Nègres qui travaillent dans les mines du Pérou [sic], sont le jouet des caprices d'un maître impitoyable, qui les échange contre un chien ou telle autre bête qu'il pourra lui plaire ». La partition est ainsi justifiée parce qu'elle est censée améliorer le sort des habitants des provinces annexées.

La politique russe est légitimée par le fait que le pays a été appelé par une diète légale et en tant que garant des traités les plus sacrés, mais surtout parce qu'il a secouru les Polonais en rétablissant « le bon ordre » qu'eux-mêmes ne pouvaient rétablir et qui menaçait de devenir un « incendie » général. Par ailleurs, la Pologne ne peut se réclamer des traités conclus entre les puissances co-partageantes et elle-même car « dès aussitôt qu'une nation tombe dans un tel état d'anarchie, qu'elle ne sait plus se gouverner elle-même et que par conséquent elle est encore moins en état de satisfaire aux engagements contractés avec d'autres peuples, elle se prive elle-même des bénéfices que le droit des gens assure par le moyen des traités aux Sociétés policées et bien ordonnées ». Si la conformité du droit des gens à l'équité naturelle ne permet pas que deux parties dépouillent un tiers sans l'avoir entendu et sans discuter préalablement leurs droits avec lui, « cela suppose un tiers qui soit en état d'entendre raison et de discuter le droit, et ne convient qu'à des personnes qui vivent dans un certain ordre social ». La Pologne, rejetée hors de la société des États européens policés, n'est donc plus capable d'y figurer comme un acteur légitime. L'auteur de L'Analyse... évite soigneusement de poser la question de la légitimé juridique des "prétentions » historiques de la Prusse, mais il admet tout de même en passant que la prescription doit composer avec la force et le droit de conquête : ainsi, il affirme que les possessions polonaises ont été le fruit des conquêtes de leurs ancêtres, et qu'il n'y a donc rien d'étonnant à ce que les puissances actuelles fassent de même.

De toute manière, l'intervention russe et la satellisation de la République de Pologne sont amplement justifiées par les « crimes des factions » depuis la mort d'Auguste III $^{62}$. Mais l'auteur de la Lettre ne se contente pas de ce terrain, il en appelle au droit des gens, à Vattel et à la pratique de l'ingérence : une puissance qui est appelée par des citoyens opprimés peut intervenir dans les affaires de ses voisins comme le montre le soutien 
de la France aux Hollandais insurgés contre l'Espagne au XVI ${ }^{\mathrm{e}}$ siècle. Les dissidents étaient opprimés, ils étaient donc en droit d'appeler la Russie à l'aide. La guerre russo-turque provoquée par la confédération de Bar selon l'auteur justifie encore plus l'indemnisation des Russes et donc le partage $^{63}$. Le droit de l'humanité n'a rien à y faire, l'intérêt des puissances prime : « Il n'y a rien de plus ridicule que de sommer l'humanité de nos voisins au point de prétendre, que pour l'amour de nous, ils dussent compromettre la sûreté de leurs états, la vie de leurs sujets, et faire le sacrifice de leurs trésors $»^{64}$. Les principes des relations entre les États sont déterminés par leur intérêt étroit et rien de plus : «C'est l'intérêt de l'État et l'intérêt personnel qui prime dans les traités », à partir du moment où toutes les puissances limitrophes y trouvent un intérêt, on ne peut éviter le partage, car «l'agrandissement est l'objectif de toutes les puissances ».

Les contemporains sont divisés sur l'attribution à la Russie ou à la Prusse du rôle majeur dans la partition. D'un côté, il leur semble que la Russie qui dominait la Pologne sans avoir besoin du partage n'avait aucun intérêt à introduire la Prusse et l'Autriche dans sa chasse gardée et que l'aile marchante du partage ne peut être que Frédéric II qui, avec son machiavélisme légendaire, a su pousser la Russie. La réputation de Frédéric II, attaquant la Silésie sans déclaration de guerre, ou ravageant avec une rare brutalité la Saxe en 1756, ne pouvait évidemment pas manquer de convaincre les contemporains de son « amoralisme » et de sa responsabilité particulière dans le partage. De l'autre, le partage de la Pologne apparaît comme un pas supplémentaire dans sa destruction en tant que barrière entre la Russie et l'Europe occidentale, destruction censée être l'objectif suivi par les Russes depuis deux siècles. L'Autriche est remarquablement hors de cause dans la plupart des commentaires, on lui reproche d'avoir participé à la curée et de s'être largement servie au passage, mais pas d'avoir joué un rôle déterminant dans la décision. Globalement, les commentateurs accusent plutôt la Prusse d'avoir joué le rôle principal dans le partage. Le personnage de Frédéric II fascine ou révolte mais il est toujours présent comme chef d'orchestre dans les textes opposés à la partition. Au Frédéric « philosophe » et « tolérant » des voltairiens, s'oppose un machiavéliste, un immoraliste, un individu sans foi ni loi, ne respectant ni Dieu, ni les lois, ni les hommes, un conquérant brutal faisant fi des règles du droit des gens lors de la guerre de Sept Ans. 
Un prince d'autant plus coupable qu'il a réfuté lui-même sa conduite dans l'Anti-Machiavel ${ }^{65}$. Il est donc non seulement un despote mais aussi un hypocrite qui fait défendre son image par ses écrivains stipendiés. On lui reconnaît néanmoins une habilité hors du commun «à manier les esprits et faire des hommes ce qu'il lui plaît » comme l'écrit Mably ${ }^{66}$, mais aussi une réussite qui force l'étonnement.

Comme l'avait remarqué Jean Fabre, il semble bien que le partage de la Pologne sonne le glas d'une certaine fascination d'une partie du public européen pour les méthodes du despotisme dit éclairé ${ }^{67}$. En tout cas, ces méthodes et ces objectifs sont l'objet d'une critique particulièrement virulente dans le débat sur la Pologne. On pourrait multiplier les exemples d'une condamnation morale de la politique, de l'amoralisme et de «l'hypocrisie » de Frédéric II et de Catherine II, citons seulement ici le roman épistolaire de Marat, Les Aventures du jeune comte Potowski, qui s'en prend avec force aux illusions du despotisme dit éclairé.

Selon Marat, la Russie est « mal peuplée, et seulement d'esclaves », son commerce nul, son agriculture médiocre. En réalité, Catherine II n'a rien fait qui mérite de l'immortaliser. Ses réformes sont peut-être spectaculairement mises en scène par les « plumes mercenaires » qui chantent perpétuellement ses louanges, mais à qui profitent-elles ? Elle a créé une école de littérature française pour une centaine de jeunes gens «mais a-t-elle établi des écoles publiques où l'on enseigne la crainte des dieux, les droits de l'humanité, l'amour de la patrie ? ${ }^{68}$ Elle encourage le luxe mais « loin d'avoir cherché à enrichir ses États, elle n'a travaillé qu'à les ruiner en dépeuplant la campagne des cultivateurs par des enrôlements forcés ». Elle a publié un nouveau code de lois, mais le nouveau est aussi affreux que le précédent et l'on n'y a rien fait pour protéger le faible contre le fort.

Si la Russie est particulièrement coupable, elle aurait eu plus de mal à s'imposer sans ses complices et, au premier chef Stanislas-Auguste Poniatowski. Le roi est «faible, inappliqué, sans fermeté, sans courage, sans soin des affaires de la nation, et sans amour pour ses peuples; on va commencer son règne par des fêtes et il continuera de même. Mollement endormi sur le trône, ou occupé de soins frivoles, il consume en délices

(65) L'insuffisance des prétentions de Sa Majesté Prussienne, op. cit., p. XIX.

(66) Gabriel Bonnot de MABLy, De la situation politique de la Pologne en 1776 dans Euvres complètes, Paris, an V, tome 13, p. 15.

(67) Jean FABre, Stanislas-Auguste Poniatowski et l'Europe des Lumières, op. cit., p. 255.

(68) Jean-Paul Marat, Les aventures du jeune comte Potowski, Paris, Renaudot, 1989, p. 128. 
ses gros revenus, rassemblant autour de lui une troupe d'artistes, de comédiens, de baladins, de virtuoses de toutes espèces, et passe son temps à régler les décorations d'une scène, l'habillement d'un acteur, l'économie d'une toilette, quand toutefois il n'est pas à languir dans les bras d'une femme $»^{69}$. Alors que l'image du roi-philosophe est largement relayée par les encyclopédistes et une bonne partie des gazettes, il existe donc un courant des Lumières qui le considère comme un homme vicieux, « énervé » et complice objectif des Russes ${ }^{70}$.

Frédéric II n'est pas mieux traité. Il est certes un grand capitaine, mais certainement pas un grand roi. La postérité lui vaudra le «mépris des sages $»^{71}$. Frédéric II « ne se soucie guère d'être les délices du genre humain, pourvu qu'il en soit la terreur. Son grand art est de savoir exterminer les hommes ». Il entend à merveille « l'art de négocier, c'est-à-dire en termes plus clairs, l'art de tromper adroitement », " rongé d'ambition, il n'a songé jusqu'ici qu'à agrandir ses États et à leur donner de la consistance ». Les despotes dits éclairés n'ont aucun honneur et veulent encore qu'on croie à leurs protestations d'honnêteté : «Séduire et tromper est leur grand art. Plus ils parlent de bonnes intentions, moins on doit les croire... $\rangle^{72}$

Leur honneur perdu, écrit l'auteur anonyme des Observations sur les conduite des cours..., ne pourra plus être regagné : ils « auront beau répandre les déclarations, et multiplier les sermons pour assurer les autres nations de l'Europe, leur conduite contre la Pologne met au grand jour leur politique, et cet exemple effrayant rendra vaines toutes leurs promesses $\gg^{73}$. Mably met en valeur la fragilité de l'édifice des despotes dits éclairés : ainsi, l'œuvre de Frédéric II risque fort de ne pas lui survivre ${ }^{74}$. Sa politique a été celle d'un "conquérant avide », qui veut se rendre puissant « sans respect pour la justice, les traités et les serments », et pas celle d'un souverain qui construit les « fondements d'un édifice solide et durable ». La politique de Catherine II est superficielle et artificielle. Elle ne remet pas en cause les bases de la misère et du despotisme russes et se contente de poser un vernis «éclairé » sur la tyrannie pour la rendre agréable.

(69) Idem, p. 89.

(70) Par exemple Rulhière, voir Alice Chevalier, Claude-Carloman de Rulhière, premier historien de la Pologne, Paris, Domat, 1939, p. 260-261.

(71) Jean-Paul Marat, Les aventures du jeune comte Potowski, op. cit., p. 138.

(72) Idem, p. 133.

(73) Observations sur la conduite..., op. cit., p. 42.

(74) Gabriel Bonnot de Mably, De la situation politique de la Pologne..., op. cit., p. 46. 


\section{Une remise en cause du « système politique » de l'Europe}

Le trait commun à la plupart des interprétations historiographiques (à part celle de Jean Fabre) évoquées en introduction au sujet de l'impact du partage de la Pologne sur l'opinion est qu'elles sous-estiment ou négligent les écrits, les impressions et les certitudes des contemporains. Or, à part les propagandistes des despotes dits éclairés, ils sont dans leur très grande majorité persuadés que la partition inaugure une ère radicalement nouvelle et un bouleversement général, non seulement des rapports de force géopolitiques territoriaux, mais aussi des représentations de l'ordre et du système européens et des règles qui fondent les relations entre les puissances.

La lettre de Vergennes à Louis XVI de 1774 est emblématique de ce sentiment de rupture. Pour le ministre des Affaires étrangères, la partition est un crime inédit dans le système politique de l'Europe. Les puissances co-partageantes ont agi avec un «mépris absolu des principes de justice et de décence $»^{75}$. La France qui ne place pas « sur la même ligne le juste et l'injuste » doit prendre en compte ce changement radical qui ruine les principes fondant la tranquillité de l'Europe :

« La postérité aura peine à croire ce que l'Europe indignée voit avec étonnement, trois puissances d'intérêt divers et opposés s'unir entre elles, et, par un abus criant de la raison du plus fort, dépouiller de ses plus riches domaines un État innocent, contre lequel on n'a d'autre titre que celui de sa faiblesse et de l'impuissance où il est de résister à la cupidité de ceux qui l'envahissent. Si la force est un droit, si la convenance est un titre, quelle sera désormais la sûreté des États ? Si une possession immémoriale, si des traités solennels qui ont fixé les limites respectives, ne peuvent plus servir de frein à l'ambition, comment se garantir contre la surprise et l'invasion? Si le brigandage politique se perpétue, la paix ne sera bientôt plus qu'une carrière ouverte à l'infidélité et à la trahison $»^{76}$.

Alors que le calme est assuré depuis le début du siècle par l'association des puissances pour empêcher la prépondérance de l'une ou de plusieurs d'entre elles, le système de sécurité collective est en train de changer et « une nouvelle combinaison prend la place de ce système d'équilibre général » : l'égalité des usurpations remplace l'équilibre des possessions et

(75) Louis Philippe de SÉgur, Politiques de Tous les Cabinets de l'Europe..., 3 vols., 4 éd., Bruxelles, 1825, tome 3, lettre de Vergennes au roi, 1774, p. 146.

(76) Idem, p. 146-147. 
de la propriété ${ }^{77}$. L'Angleterre est accusée d'avoir favorisé le crime en refusant une action concertée avec la France. Les grandes puissances ont montré une « défection générale » à l'égard des principes. La France doit se constituer en vengeur des injures faites « aux droits sacrés de la justice et de la propriété ». Pour Vergennes, le partage est donc bien fondamentalement un crime contre les bases du « repos et de la tranquillité de l'Europe », c'est-àdire contre la propriété, la souveraineté, la liberté et l'existence des nations ${ }^{78}$. Il reprend ici une idée déjà développée par Favier qui écrivait l'année précédente : «La position respective de la Pologne à l'égard de la France et de toutes les autres puissances de l'Europe, est donc celle d'un membre retranché de la société, d'un citoyen privé de ses droits naturels, réduit à l'esclavage, mort civilement, et par conséquent n'ayant plus dans l'ordre politique ni propriété ni personnalité $»{ }^{79}$. Le partage de la Pologne est une brèche essentielle dans les "droits des nations », expression que l'on retrouve dans les instructions au baron de Breteuil envoyé en Autriche ${ }^{80}$.

C'est la raison pour laquelle la situation de la Pologne n'est pas pensée comme une affaire locale ou régionale, mais qu'elle regarde l'ensemble de l'Europe. Cette conviction s'affirme dès le début de la guerre russo-turque, par exemple chez l'abbé Baudeau qui écrit dans les Éphémérides du citoyen que les affaires de Pologne doivent être regardées par toutes les nations « comme très importantes pour la paix de l'Europe et le bonheur de l'humanité $\rangle^{81}$. Après la partition, John Lind proclame que la " cause de la Pologne est devenue celle de toute l'Europe, et particulièrement des États du second ordre ${ }^{82}$. C'est l'équilibre général du continent qui est menacé : la ligue des puissances du Nord contre celles du Sud remet en cause le système de sécurité collective ${ }^{83}$. Linguet écrit en 1773 :

«Ce qui se passe aujourd'hui dans le Nord fixe l'attention de toute l'Europe : il n'est point de nations qui n'aient un intérêt, soit présent, soit futur, à l'événement qui doit décider du sort de la république de Pologne ;

(77) Ibid., p. 150

(78) Oliver Murphy, Charles Gravier, Comte Vergennes. French Diplomacy in the Age of Revolution 1719-1787, Albany, 1982, p. 213.

(79) Louis Philippe de SÉGur, Politiques de Tous les Cabinets de l'Europe..., op. cit., tome 2, p. 286.

(80) Albert Sorel, Recueil des instructions aux ambassadeurs et ministres de France, I, Autriche, Paris, 1884, p. 487.

(81) Nicolas Baudeau, Éphémérides du Citoyen, Milan, Feltrinelli reprints, 1969, tome 2, 1770 , p. 17.

(82) John Lind, Letters Concerning..., op. cit., p. 189, notre traduction.

(83) Idem, p. 303. 
l'Allemagne relativement à sa liberté ; la France à cause de l'influence qu'elle a eue jusqu'à présent dans les affaires politiques de l'Europe ; la Suède et le Danemark, parce qu'ils ont des prétentions à faire valoir et des possessions à conserver; l'Angleterre et la Hollande plus qu'aucune autre, vu leur commerce. Un intérêt plus pressant, celui de l'humanité, fait désirer à toutes les âmes sensibles qu'un changement heureux de gouvernement indemnise les Polonais de la perte d'une partie de leur territoire dont ils sont menacés $»^{84}$.

Pour Carracioli en 1775: «La Pologne est maintenant un vaste théâtre où l'on voit la scène la plus touchante, et il n'y a point d'Européen qui ne doive se regarder comme en étant le spectateur $\gg{ }^{85}$. Le Mercure historique et politique contenant l'état présent de l'Europe parle d'une révolution « considérée respectivement au système général de l'Europe ${ }^{86}$.

De même, les commentateurs mettent presque tous en valeur le caractère inédit et fondateur du partage. L'abbé Joubert écrit ainsi : «la révolution actuelle de la Pologne forme une époque dont l'histoire ne nous fournit point d'exemple ${ }^{87}$. L'humiliation de la Pologne, « le partage de dix de ses provinces, proposé sans prétexte, consommé avec tranquillité entre trois de ses voisins, et considéré avec indifférence par les autres potentats de l'Europe » est l'un des événements les plus extraordinaires de 1'histoire des siècles derniers, assure Linguet ${ }^{88}$.

Les écrits des publicistes et des commentateurs sont imprégnés de cette impression de bouleversement des fondements de l'Europe. L'auteur anonyme de L'Examen du système des cours de Vienne, de Pétersbourg et de Berlin... définit ainsi la nature de la rupture : « L'espèce de république, que formaient les Nations européennes, n'est plus qu'un beau fantôme. Une anarchie destructive de tout repos des souverains et du bonheur des peuples y succède ; et le tableau effrayant des temps gothiques, que l'histoire a conservé, se représentera de nouveau sur la surface de cette partie du monde $»^{89}$. De nouveaux rapports de forces « donneront lieu à de nou-

(84) Simon Nicolas Henri Linguet, Considérations politiques et philosophiques, sur les affaires présentes du nord et particulièrement sur celles de Pologne, Londres, 1773, p. 2 et suivantes.

(85) Louis Antoine Caraccioli, La Pologne, telle qu'elle a été, telle qu'elle est, telle qu'elle sera, Varsovie et Poitiers, 1775, p. VI.

(86) Mercure historique et politique contenant l'état présent de l'Europe, janvier 1773.

(87) Pierre Joubert, Histoire des révolutions de Pologne depuis la mort d'Auguste III jusqu'à l'année $1775 \ldots$, Warsovie, 1775,2 vol. in- $8^{\circ}$, p. 7.

(88) Simon Nicolas Henri Linguet, Annales politiques, civiles et littéraires du XVIII siècle, 1777-1792, Genève, Slatkin reprints, 1970, 10 vol., vol 1, « Réflexions préliminaires », p. 6.

(89) Examen du système des cours..., op. cit., Londres, 1773, p. 9. 
veaux systèmes d'association, et régleront arbitrairement les constitutions des États et leurs propriétés », toutes les puissances secondaires « seront exposées à des inquiétudes continuelles sur leur sort, au moindre soupçon de négociations secrètes $\rangle^{90}$. L'indécent mépris des puissances co-partageantes pour le droit des peuples, les traités et les principes les plus sacrés du repos sont également un exemple fâcheux d'immoralité donné aux peuples : «À ces incertitudes des propriétés, à ces défiances mutuelles, à ce renversement général de tout ordre dans la société des corps politiques, conséquences naturelles du système, ajoutons encore les suites non moins naturelles des impressions qu'il fait dans l'esprit des peuples ».

Le nouveau système de convenance crée un état de guerre et d'anarchie permanente qui se retournera contre ses défenseurs, prédit l'auteur anonyme des Observations sur les déclarations... :

«Si pour dépouiller une Nation, il suffit de se liguer secrètement contre elle, de se communiquer les prétentions qu'on forme à sa charge, sans lui en donner connaissance, si la prescription n'a pas lieu entre les souverains, si une possession paisible de plusieurs siècles, ne sert plus de titre ; si les traités ne produisent plus d'engagements, n'est-il pas évident que l'Europe sera dans un état continuel de guerre; que tous les liens des sociétés humaines sont rompus, que les corps politiques des nations n'ont plus rien d'assuré, que toutes les règles d'équité sont détruites, et qu'il ne reste, sur les débris de la justice, que l'affreuse anarchie de la force et de l'audace? Malheur aux puissances qui donnent des exemples aussi funestes! Elles devraient prévoir qu'on est autorisé à les suivre contre elles-mêmes et qu'elles peuvent être un jour la victime des erreurs qu'elles érigent en système, pour favoriser leur intérêt du moment $»^{91}$.

Le partage de la Pologne met donc essentiellement en jeu le droit public de l'Europe et ses fondements : les monarques se donnent les titres que la force leur permet d'usurper. En donnant ainsi l'exemple du mépris pour les bases du consensus qui fondent le « repos » et la « tranquillité », les rois poussent les peuples à faire de même. Linguet lie ainsi la cause polonaise et la cause américaine: "Le partage de la Pologne est l'exemple le plus frappant qui ait été encore donné de la facilité avec laquelle les Souverains se créent des titres ; l'insurrection des Américains est une preuve encore plus

(90) Ibid., p. 11.

(91) Observations sur les déclarations..., op. cit., Londres, 1773, p. 36. 
frappante que les peuples peuvent s'arroger la même faculté $\rangle^{92}$. Il ironise sur le mauvais exemple donné aux sujets des rois, le partage de la Pologne peut ainsi paradoxalement aboutir à une moralisation des souverains effrayés : « Si tous les particuliers se mettaient ainsi à examiner comment on peut dépecer les Empires, il en résulterait cependant un bien général. Les Souverains voyant avec quelle facilité l'injustice les dépouille eux-mêmes quand elle est jointe à la force, en viendraient peut-être à sentir que celle-ci ne doit pas seule avoir leur confiance : l'équité leur paraîtrait mériter un peu plus d'égards et leurs sujets y gagneraient autant que leurs voisins $»^{93}$.

Les écrits des défenseurs de la Prusse répondent également sur le terrain du droit des gens et des conséquences de la partition, mais, évidemment, pour en minorer l'importance. L'auteur de l'Analyse d'une brochure... qui répond à celui des Observations... estime que le discours sur la subversion de l'ordre européen est révélateur d'un « délire » politique, d'un « esprit de vertige » potentiellement producteur de désordres. Le partage de la Pologne ne bouleverse en rien l'Europe, mais une coalition générale des puissances du Sud contre celles du Nord plongerait le continent dans la guerre perpétuelle. Les seuls perdants sont en réalité les petits tyrans, responsables de l'anarchie et des malheurs de leur pays ${ }^{94}$.

Apparemment, tel n'était pas le point de vue de la plupart des souverains des puissances secondaires. Les sources diplomatiques françaises disent toutes l'indignation et la frayeur engendrées par la partition parmi les princes de l'Europe. Ainsi l'envoyé auprès de l'électeur de Mayence écrit en 1774 : «L'Électeur a trouvé le partage de la Pologne injuste et il en a été effrayé ; en effet, cet exemple doit faire craindre aux États d'Allemagne d'entrer tôt ou tard dans un système de convenances $»^{95}$. Les instructions pour Montmorin en poste à Trèves expriment exactement les mêmes craintes ${ }^{96}$. La Poméranie semble particulièrement visée dans la mesure où le récent coup d'État de Gustave III paralyse la Suède pour un moment au moins. Dantzig surtout est l'objet de l'attention des diplomates. On s'inquiète en Angleterre des conséquences de l'expansion prussienne sur le commerce en Baltique, fondamental pour les milieux marchands de Londres, mais aussi d'une possible tentative d'agression contre le Hanovre.

(92) Simon Nicolas Henri Linguet, Annales politiques, civiles et littéraires..., op. cit., vol 9, p. 497

(93) Idem, vol 1 « Réflexions préliminaires », p. 138-139.

(94) Analyse d'une brochure, qui porte le titre d'Observations sur les déclarations..., op. cit.

(95) Georges Livet, Recueil des instructions aux ambassadeurs et ministres de France, XXVIII, (États allemands tome 1 : Mayence), Paris, 1962, p. 232.

(96) Ibid., tome 3, Électorat de Trèves, Paris, 1963, p. 251. 
Le « système de convenance » semble être le prélude à un vaste mouvement de rationalisation de l'espace politique liquidant les petits États au profit des plus grands, programme souvent défendu par les partisans des despotes dits éclairés. Ceux que j'ai appelés ailleurs les partisans des « grandes masses » sont en effet les avocats d'un redécoupage territorial radical qui modifierait le Saint-Empire et en finirait avec la Turquie européenne ${ }^{97}$. Les commentateurs en sont tout à fait conscients et évoquent presque tous les menaces qui pèsent sur ces États. Ainsi, l'auteur des Observations sur les déclarations... écrit peu après la partition : «Le traité de partage pour les provinces de Pologne, menace également le Danemark, la Suède, le Corps germanique, la Hollande, la Suisse, les Princes d'Italie, enfin l'Europe entière. [...] [Les puissances secondaires] doivent sentir que si elles ne se confédèrent pas de bonne heure pour rompre la ligue des cours de Vienne, de Berlin et de Pétersbourg, elles tomberont, les unes après les autres, sous le joug de ces trois puissances, et qu'il n'y a qu'une alliance offensive, prompte et générale, qui puisse les garantir de leur chute $»^{98}$. Galiani prédit un effondrement européen, les républiques et les petites monarchies risquent de subir le même sort que la Pologne et si la convenance et le droit du plus fort s'imposent, alors les Européens risquent de le regretter et nous serons, ajoute-t-il ironiquement, Chinois « dans cent ans au plus $»^{99}$ !

Les images s'emparent de cette actualité. La gravure de Noël Le Mire, Le Gâteau des Rois, représente les trois despotes découpant la carte de la Pologne et Stanislas-Auguste éploré dont la couronne vacille. Une figure féminine représentant peut-être la justice ou la renommée s'enfuit dans le ciel, comme refusant de voir s'accomplir le crime. Selon Jean Fabre, d'autres dessins représentaient Stanislas dépouillé « de ses vêtements par les trois complices, sous un ciel d'orage, devant une caverne de voleurs, tandis que la justice prostrée, avait lâché ses balances et son glaive, pour cacher de ses bras son visage en pleurs ». La mode suit la politique, les femmes portent même des robes «à la polonaise » fabriquées à partir de « trois morceaux de tissu symbolisant le partage $»^{100}$ !

La perspective de nouveaux partages découlait de l'idée, largement répandue dans un premier temps, que l'union des trois puissances co-par-

(97) Marc Belissa, Fraternité Universelle et Intérêt National, 1713-1795. Les cosmopolitiques du droit des gens, Paris, Kimé, 1998, p. 97 et suivantes.

(98) Observations sur les déclarations des cours de Vienne, op. cit., p. 44.

(99) Cité dans Jean Fabre, Stanislas-Auguste Poniatowski et l'Europe des Lumières, op. cit., p. 359 .

(100) Lydia SCHER-ZEMBITSKa, L'aigle et le phénix : un siècle de relations franco-polonaises : 1732-1832, Paris, CNRS, 2001, p. 17. 
tageantes ne pouvait pas durer éternellement et que leur crime recelait les germes d'un conflit général en Europe de l'Est pouvant embraser tout le continent ou bien les inciter à de nouveaux partages en Allemagne, en Turquie et dans l'aire Baltique. Les prédictions pessimistes sur le sort de la Pologne l'emportaient largement sur les quelques optimistes qui y voyaient une possibilité de redressement pour la République : la perspective d'un second partage semblait, hélas, très probable à de nombreux contemporains. Les longues instructions de 1774 pour le baron de Breteuil, envoyé en Autriche, reviennent sur ce pronostic. Selon ce texte, l'entente des trois puissances est factice et ponctuelle. La partition n'a pas renforcé l'Autriche qui a compris qu'elle avait été dupée: "Les royaumes de Galicie et de Lodomérie ont affaibli la monarchie autrichienne, en énervant l'ensemble de sa défense et en consommant une partie des moyens nécessaires à la protection de ses anciennes possessions et qui seront toujours insuffisantes pour les nouvelles. L'enthousiasme des Grecs [les orthodoxes], répandus dans les unes et dans les autres, est encore un puissant ressort dont la Russie saura entretenir l'activité $»^{101}$. La Prusse « a pris un accroissement énorme », ces avantages ont rompu « toute espèce de proportion avec les acquisitions autrichiennes ». Le roi de Prusse a réuni ses États en « une seule masse et a facilité les mouvements du centre aux extrémités » alors que les acquisitions autrichiennes sont indéfendables et séparées des provinces autrichiennes par des obstacles naturels ${ }^{102}$. Les instructions rapportent que la Prusse a déjà le projet scandaleux de procéder à un deuxième partage et d'encourager le démembrement immédiat de la Turquie d'Europe. Les instructions du 20 novembre 1776 pour le duc de la Vauguyon envoyé en Hollande sont également éloquentes quant à l'impression générale que l'Europe est entrée dans une ère de transition dans laquelle tout ou presque peut se produire : « La Suède mal affermie encore dans sa nouvelle constitution, craint le ressentiment de ses voisins, [...] la Porte ottomane, nulle par sa faiblesse, est un objet de convoitise pour ses voisins, [...] la Pologne, en proie à trois grandes puissances, semble devoir semer parmi elles un germe de discussion dont le développement causera tôt ou tard l'explosion la plus dangereuse ${ }^{103}$.

(101) Albert SoReL, Recueil des instructions aux ambassadeurs et ministres de France, I, Autriche, op. cit., p. 457.

(102) Idem, p. 462.

(103) Louis ANDRÉ et Émile BouRgEOIs, Recueil des instructions aux ambassadeurs et ministres de France, XXIII, Hollande, tome 3, Paris, 1924, p. 334. 
Les optimistes considèrent que la division inévitable entre les trois puissances peut permettre à la Pologne d'en profiter et de se relever du désastre. En cas de décès d'un des souverains ou d'une guerre générale, elle pourrait s'appuyer sur l'Autriche ou sur la Russie contre la Prusse, ou bien obtenir le soutien de la France, de l'Angleterre et de la Suède, enfin dégrisées et décidées à ne pas laisser l'équilibre de l'Europe se dégrader encore plus. Pour pouvoir profiter d'un éventuel retournement de situation, il est donc nécessaire de se tenir prêt et donc de construire un État plus fort en en finissant avec «l'anarchie». Le programme de réforme de StanislasAuguste semble aller dans ce sens. La création du comité permanent, de la commission d'éducation nationale en octobre $1773^{104}$, les projets économiques inspirés par la physiocratie, la stabilisation politique réalisée dans la diète de 1776, pouvaient en effet indiquer que la Pologne allait se relever parmi les puissances et au moins reconstruire une république sur le territoire qui lui restait, qui était encore tout à fait étendu, après tout.

Cédant à la force de la nécessité, l'auteur de la Lettre historique et politique d'un gentilhomme polonais... invite les Polonais à s'unir au roi et à ses réformes ${ }^{105}$. D'autres commentateurs veulent faire d'un mal un bien en évoquant la possibilité que le crime de la partition « tourne au bien de l'humanité » comme l'écrit Deleyre et aboutisse notamment à briser « les chaînes de la partie la plus laborieuse » des peuples des provinces usurpées et des autres ${ }^{106}$. Ces pronostics plus ou moins heureux suscitent les critiques, et même l'ironie, de Mably. Dans De la situation politique de la Pologne en 1776, écrit au retour de son voyage sur place, Mably tempère l'enthousiasme des réformateurs : «Croire que votre république subsiste, parce que vous avez encore un territoire, un roi, un sénat, un conseil permanent, vos grands officiers, et qu'on n'a pas proscrit les noms de Diète, de nonces et de diétines, ce serait une erreur, et prendre une ombre pour le corps ». Car dès qu'elle perd son indépendance, toute société est dissoute, ce qui est le cas de la Pologne qui n'est plus qu'une province d'une puissance étrangère. Renforcer les pouvoirs du roi revient à renforcer le complice de la Russie ${ }^{107}$. Même en cas de conflit entre ses voisins, la répu-

(104) Celle-ci, financée par les fonds provenant de la compagnie de Jésus désormais dissoute, put lancer un programme de réforme pédagogique et économique, inspiré par Konarski et les disciples des physiocrates français. Elle joua un rôle important par la suite.

(105) Lettre historique et politique d'un gentilhomme polonais..., op. cit., p. 68.

(106) Alexandre Deleyre, Tableau de l'Europe, pour servir de supplément à l'histoire philosophique et politique des établissements et du commerce des Européens dans les deux Indes, Maestricht, 1774, p. 17.

(107) Gabriel Bonnot de MABly, De la situation politique..., op. cit., p. 5. 
blique polonaise n'a plus rien à attendre parce que le républicanisme et le patriotisme y sont morts et que la plus grande partie de sa noblesse qui a, seule, les droits de citoyen s'accommode fort bien de la partition, car elle ne remet pas en cause ses intérêts de propriétaire et la possession de ses serfs. Les Polonais ne doivent rien attendre des puissances européennes qui ne s'opposeront pas plus à un second partage qu'au premier et ne feront rien pour soutenir les réformes ou relever la Pologne. La probabilité d'un second partage à court ou moyen terme est donc très forte : "Ces idées de république et de patriotisme qui fermentent encore dans quelques têtes, s'effaceront peu à peu; sans trouble et sans révolution, la Pologne se trouvera partagée, et peut-être que ce siècle doit servir d'époque à cet événement sinistre $»^{108}$.

Dans Le Banquet des Politiques, Mably remet vivement en place les trois gentilshommes partisans des réformes avec lesquels il discute en leur rappelant que si les réformes permettaient réellement de reconquérir la liberté, les Russes ou les Prussiens ne se feraient pas faute de les empêcher. Les « niaiseries économiques » des partisans du roi servent à couvrir la montée du « despotisme » qui, en cas de conflit, préférera toujours se réfugier dans les bras des Russes plutôt que de se mettre à la tête d'un mouvement patriotique ${ }^{109}$. Rien à espérer de ce côté là donc. L'article « Pologne » de l'Encyclopédie méthodique est également très peu consolateur : « La Pologne sera encore obligée de subir la loi la plus dure, toutes les fois que ses voisins voudront se réunir pour la lui dicter $\gg^{110}$. Sans armée, sans argent, dotée d'un mauvais gouvernement, la République ne se relèvera pas : « Ses infortunes, loin de cesser, s'accroîtront vraisemblablement, à moins que, par quelque cause imprévue, elle ne devienne une monarchie héréditaire, ou une république bien ordonnée, ou, ce qui est plus probable, qu'elle ne soit conquise par ses puissants voisins ».

La perspective d'une disparition totale de la République polonaise est donc ouverte dès après la première partition, celle de la résistance des Polonais à leurs conquérants aussi. On connaît l'apostrophe fameuse de Rousseau aux confédérés qui leur conseillait «d'infuser pour ainsi dire, dans toute la nation l'âme des confédérés » et d'établir «tellement la République dans le cœur des Polonais, qu'elle y subsiste malgré tous les

(108) Idem, p. 8.

(109) Gabriel Bonnot de Mably, Le Banquet des Politiques, dans Euvres complètes, Paris, an $\mathrm{V}$, tome 13 , p. 110-111.

(110) Nicolas Desmeuniers, Encyclopédie méthodique : économie politique et diplomatique, Paris 1784-1786, 4 vol., article Pologne, p. 634. 
efforts de ses oppresseurs ». Il concluait: "Vous ne sauriez empêcher qu'ils ne vous engloutissent, faites au moins qu'ils ne puissent vous digérer $\gg{ }^{111}$. Reprenant ces conseils, Caraccioli appelle lui aussi les Polonais à imiter le peuple hébreu en exil : l'amour de la liberté des braves sarmates ne s'éteindra jamais, « semblables aux Juifs pendant la captivité de Babylone, ils ne s'occuperont que de Jérusalem et ils regarderont tout pays, qui ne sera point la Pologne, comme une terre étrangère. Leur cœur et leur âme seront toujours à Varsovie. Ce sera le centre de leurs désirs. L'ombre de leur république leur apparaitra dans le temps même qu'elle ne subsistera plus, et dès que l'occasion se présentera, sans être ni rebelles ni cabaleurs, ils la saisiront avec la plus grande avidité, pour recouvrer leur chère liberté $\rangle^{112}$.

Ces analyses des conséquences du partage de 1772 sont reprises par les journalistes, les publicistes ou les députés de la période révolutionnaire, notamment à partir du déclenchement de la guerre entre la France et les puissances coalisées. Les contemporains de la Révolution française étaient parfaitement conscients de la double nature des guerres révolutionnaires : rupture fondamentale avec l'ordre ancien mais aussi conséquences de son effondrement antérieur. On retrouve cette dialectique aussi bien chez les contre-révolutionnaires que chez les républicains français. Or, pour beaucoup de ces commentateurs, en particulier dans les années 1795-1800, c'est bien le premier partage de la Pologne qui est à l'origine de cette destruction (avec le renversement des alliances de 1756 et la guerre d'Indépendance américaine le plus souvent).

Burke avait déjà expliqué en 1772 que le premier partage en anticipait sans doute d'autres, et que si la Pologne n'avait été qu'un "petitdéjeuner », les puissances co-partageantes « dîneraient » ailleurs ${ }^{113}$. Il reprend cette idée en 1796 accusant les «politiques diplomates » français (il vise les opposants à l'alliance autrichienne) d'avoir renversé la monarchie pour se venger de son incapacité à profiter du partage de la Pologne ou de l'imiter en s'emparant des Pays-Bas ${ }^{114}$. Pour Burke, le partage de 1772 inaugure une ère de bouleversements de la carte politique de l'Europe dans laquelle les anciennes possessions ne sont plus à l'abri des usurpations.

(111) Jean-Jacques Rousseau, Considérations sur le gouvernement de Pologne, dans Euvres complètes, tome III, Paris, Pléiade, 1964, p. 959-960.

(112) Louis Antoine Caraccioli, La Pologne, telle qu'elle a été..., op. cit., p. 35.

(113) David B. Horn, British Public Opinion..., op. cit., cité p. 13 : « Pray, dear sir what is next? These powers will continue armed. Their armies must have employment. Poland was but a breakfast, and there are not many Polands to be found. Where will they dine? »

(114) Edmund Burke, Lettre à un membre de la chambre des Communes du Parlement d'Angleterre sur les négociations de paix ouvertes avec le Directoire, Paris, sd (1796), p. 115. 
Même si les contre-révolutionnaires accusent d'abord la Révolution française d'avoir détruit l'ordre européen, ils sont nombreux, à l'image de Burke, à admettre qu'elle n'est pas la seule coupable et que l'équilibre de l'Europe avait déjà commencé à se disloquer avant 1789. Pour l'auteur de L'Antidote au congrès de Rastadt (sans doute l'abbé de Pradt en 1798), le système de l'Europe reposait sur les traités d'Oliva, de Westphalie et d'Utrecht, or ces trois bases ont été détruites : les traités de Bâle, de Campoformio et le congrès de Rastatt "ont sanctionné le désordre général, introduit par le premier partage de la Pologne et confirmé par la guerre d'Amérique ${ }^{115}$. L'idée que le partage de la Pologne est l'événement majeur qui a enclenché le processus de destruction de l'ordre d'Ancien Régime est partagée par certains journalistes de droite comme Lacretelle ${ }^{116}$. S'il accuse surtout l'esprit des Lumières d'avoir favorisé la destruction de l'ordre de Westphalie, il met en cause l'avidité des puissances co-partageantes qui se sont emparées des "nouvelles maximes » pour détruire l'équilibre de l'Europe. Même son de cloche en l'an V dans un journal crypto-royaliste comme La Quotidienne qui se demande par ailleurs « comment les grandes puissances, dont les droits paraissaient reposer d'une manière immuable sur le traité de Westphalie, ont été spectatrices si tranquilles de ce partage de la Pologne, qui a dérangé tous les rapports, toutes les relations, et a effacé un état si considérable de la carte de l'Europe $\gg^{117}$.

L'image de l'ordre européen d'avant 1789 est évidemment très différente chez les républicains. À l'image idéalisée des contre-révolutionnaires, ils opposent un tableau plus sombre des relations entre les puissances. Il s'agit là d'un des thèmes importants du débat politique, de 1795-1796. Le constat de départ est le même que chez les contre-révolutionnaires : l'ordre de Westphalie et d'Utrecht a disparu et aucune structure nouvelle n'est venue le remplacer. La conscience des acteurs de vivre un moment de bouleversement de l'ordre politique européen et de traverser une période d'anomie internationale est donc aiguë chez les républicains. Le partage de la Pologne revient ici une fois de plus de manière récurrente. Rétrospectivement, il marque pour la plupart des commentateurs le début de la fin de l'Europe moderne. Cette « fusion de tant de

(115) Dominique de PRADT, Antidote au congrès de Rastadt ou plan d'un nouvel équilibre en Europe, Londres, 1798, p. 17.

(116) Jeremy Popkin, The Right-Wing Press in France, 1792-1800, University Of North Carolina Press, 1980, p. 161.

(117) « Mes rêves », La Quotidienne, $\mathrm{n}^{\circ} 244$ du 6 nivôse an V (26 décembre 1796). 
puissance » comme l'écrit le rédacteur de la Décade philosophique a «changé la face du monde politique $»^{118}$. Le crime commis au nom du prétendu équilibre des puissances est emblématique du « désordre » créé par les rois. Le démembrement de la Pologne n'est qu'un élément d'un gigantesque plan d'asservissement de tous les peuples, c'est un crime immoral et barbare contre les Polonais mais c'est surtout, comme l'écrit Le Journal des patriotes de 89, " une violation de tout ce qu'il y a de sacré parmi les hommes ». Cet événement «a rompu, je ne dis pas l'équilibre dont on ne cesse de parler en Europe ; cet équilibre n'existe pas, n'a jamais existé ; mais il a rompu cette digue que la nature semblait avoir établie, et que, depuis plus d'un siècle, la politique européenne conservait avec une espèce de religion contre les inondations de la Russie ${ }^{119}$. L'irruption de la Russie - considérée comme semi-barbare - dans la politique continentale est la preuve de la subversion de tout ordre. Le Moniteur affirme que l'objectif de la coalition n'était pas seulement de détruire la Révolution française mais aussi de permettre le deuxième partage de la Pologne, la destruction de l'Empire ottoman et le vol des colonies françaises et hollandaises. Les républicains accusent Louis XV et Louis XVI d'avoir laissé s'effondrer l'ordre dont ils étaient garants. La cour de France a permis le partage de la Pologne, a laissé les patriotes hollandais seuls face à leur Stadhouder, et a fermé les yeux devant les usurpations des Habsbourg au mépris de sa fonction traditionnelle de puissance garante de la «liberté germanique ». Comme l'écrit Eschassériaux, la France n'a joué qu'un rôle passif dans la politique européenne, car elle était gouvernée par des monarques ambitieux et enchaînée par des traités « impolitiques », elle n'a pas pu donner à son action la «fermeté de la sagesse qui appartient à une nation grande et magnanime $»^{120}$.

Ni franchement contre-révolutionnaire, ni favorable au régime directorial, Dumouriez renvoie, quant à lui, dos-à-dos monarques et révolutionnaires dans son Tableau spéculatif de l'Europe en 1798. Tous ont contribué à détruire l'ordre : le traité franco-autrichien de 1756 a donné le branle au désordre en liquidant l'équilibre allemand, la guerre anglo-américaine puis le partage de la Pologne ont anéanti le système de sécurité

(118) La Décade philosophique, $\mathrm{n}^{\circ} 63$ du 20 janvier 1796 (30 nivôse an IV), p. 178.

(119) Le Journal des patriotes de 89, $\mathrm{n}^{\circ} 119$ du 24 frimaire an IV (15 décembre 1795), p. 485 .

(120) Joseph Eschassériaux, « Des intérêts de la République française et de toutes les puissances de l'Europe » dans Moniteur, tome XXVII, $n^{\circ} 138$, p. 379. 
collective, et enfin la Révolution qui a détruit ce qui n'avait été qu'ébranlé ${ }^{121}$. La politique directoriale d'usurpation n'est d'ailleurs selon lui qu'une imitation du «système de convenances » que les rois ont appliqué à la Pologne.

Le partage de la Pologne apparaît donc à tout un courant d'opinion au sein des Lumières, et au-delà pendant la Révolution française, non comme un fait anodin dans une Europe hobbesienne dominée par les intérêts égoïstes des puissances, mais comme un crime contre les droits des nations, le droit des gens, la prescription, la propriété des peuples et d'une manière générale contre l'idée d'une politique morale. Ces commentateurs insistent fortement sur le caractère inédit de la rupture juridique que représente la partition. Elle est l'affirmation brutale d'un amoralisme absolu et sans fards dans les relations entre les États. Les prétentions et les droits revendiqués par les puissances co-partageantes ne sont que l'habillage grossier d'un « système de convenances » qui menace l'Europe. La gène et le silence relatifs des apologistes du despotisme dit éclairé - qui voient, quant à eux, la partition comme une nécessité historique et comme un fait découlant du jeu des rapports ordinaires entre les États - est sans doute l'indice d'un tournant de l'opinion européenne visà-vis des « héros » de Voltaire. Certes, l'admiration vis-à-vis de Frédéric II ou de Catherine II ne disparaît pas, mais elle est sérieusement tempérée par une condamnation assez largement partagée de leur politique extérieure conquérante et destructrice des droits des peuples.

Le premier partage de la Pologne est également analysé comme un événement capital mettant essentiellement en cause les principes juridiques, politiques et moraux à la base du "système politique » européen. Il semble inaugurer une ère de troubles, de remises en cause des positions acquises par les puissances, de bouleversements territoriaux à l'échelle d'abord, régionale, puis continentale. Le "système de convenance» remet en cause le « repos » et la «tranquillité » de l'Europe, bases de l'équilibre fondé à Utrecht. Le démembrement apparaît comme la preuve que les droits des nations entrent objectivement en conflit avec les intérêts des monarques et semble introduire une nouvelle forme de régulation - ou de dérégulation - au sein de la société des États de l'Europe.

En 1789, le jacobin Peyssonnel voyait dans le partage de la Pologne le moment où la véritable nature immorale et anarchique de la politique 
des rois s'est dévoilée à l'Europe entière ${ }^{122}$. En 1816, Piotr Maleszewski, le gendre polonais du conventionnel Garran de Coulon, insistait lui aussi sur le caractère primordial du tournant de la première partition :

« Si les puissances prenaient part au sort déplorable de cette malheureuse nation, si elles blâmaient les procédés de ces voisins, elles donnaient en même temps le conseil de céder aux circonstances et de subir la loi du plus fort. Les cabinets ne vécurent depuis que sous cette loi. [...] L'Autriche, la Prusse et la Russie, en signant le traité de partage, ont violé ceux d'Oliva, de Wehlau, ont violé tous les traités. Les monarques de l'Europe qui ne s'opposèrent pas de toutes leurs forces à ces violations ont contribué à la ruine de ces principes, de ces conventions qui formaient le système de la politique extérieure des États. En laissant opprimer, anéantir un peuple que recommandaient tant d'intérêts, tant de souvenirs, ils ont forcé les peuples à s'occuper eux-mêmes de la conservation de leur existence et de leurs droits. De là les révolutions qui ont signalé la fin du siècle et qui durent encore aujourd'hui. Qui devront-ils en accuser ? $\gg^{123}$

Les révolutions de la fin du XVIII siècle sont donc, selon lui, le fruit de la destruction des principes de consensus qui fondaient le «système politique » de l'Europe. Les despotes dits éclairés ont contribué eux-mêmes à fragiliser les bases de leur pouvoir. Les peuples ont compris qu'ils ne devaient rien attendre des rois et que la paix et la préservation des «propriétés des nations » ne pouvaient être garanties que par elles-mêmes.

Le premier partage de la Pologne de 1772 peut donc être considéré comme un des moments les plus importants de mutation des manières de penser le « système politique » de l'Europe et les règles qui le structurent. Une partie au moins des contemporains y ont vu un événement fondateur, ouvrant une ère nouvelle : celle des révolutions.

Marc Belissa

Université Paris X Nanterre 200 Avenue de la République, 92000 Nanterre mbelissa@club-internet.fr

(122) Charles de Peyssonnel, Situation politique de la France et ses rapports actuels avec toutes les puissances de l'Europe, Paris, 1789, 2 vol., p. 99.

(123) Piotr Pawel Maleszewski, Essai historique et politique sur la Pologne, depuis son origine jusqu'en 1788, Paris, Fournier, 1832, p. 271. 